\title{
Perioperative Short Term Prophylaxis against Deep Vein Thrombosis after Major Abdominal Cancer Surgery: Retrospective Cohort Study
}

\author{
Nuray Colapkulu-Akgul ${ }^{1}$, lbrahim Ali Ozemir ${ }^{2}$, Damla Beyazadam², and Orhan Alimoglu ${ }^{2}$ \\ ${ }^{1}$ Department of General Surgery, Kocaeli Gebze Fatih Public Hospital, Kocaeli, ${ }^{2}$ Department of General Surgery, lstanbul Medeniyet \\ University, Goztepe Prof Dr Suleyman Yalcin City Hospital, lstanbul, Turkey
}

Purpose: The aim of this study is to evaluate the outcomes of pharmacological thromboprophylaxis given for short-term duration to the patients who underwent major abdominal surgery for colorectal and gastric cancer.

Materials and Methods: This retrospective cohort study was performed in consecutive patients who underwent major abdominal surgery for colorectal and gastric cancer and received short-term pharmacological thromboprophylaxis during hospital stay were enrolled. Complete duplex ultrasonography of the lower limbs was performed for all patients to investigate both symptomatic and asymptomatic deep vein thrombosis (DVT).

Results: Overall, 278 patients were evaluated for inclusion and 62 colorectal and 27 gastric cancer patients were enrolled. Of 89 patients, the incidence of total and symptomatic DVT was $4.5 \%$ and $2.2 \%$, respectively. The patients with symptomatic DVT were diagnosed within the first four months. The incidence of coronary artery disease, mucinous adenocarcinoma and vascular tumor invasion were significantly higher in patients with DVT (P-values $<0.001,0.009$, and 0.02, respectively). Conclusion: Short-term pharmacological thromboprophylaxis after major abdominal surgery for colorectal and gastric cancer does not increase symptomatic DVT rates of patients with low Caprini score. Postoperative DVT surveillance may benefit patients with coronary artery disease, mucinous adenocarcinoma or vascular invasion of the tumor.

Key Words: Venous thrombosis, Colorectal neoplasms, Stomach neoplasms, General surgery, Prophylaxis
Received September 3, 2021

Revised December 3, 2021

Accepted December 19, 2021

Published on December 31, 2021

Corresponding author: Nuray Colapkulu-Akgul Department of General Surgery, Kocaeli Gebze Fatih Public Hospital, Osman Yllmaz 1, İstanbul Cd. No:127, Gebze, Kocaeli 41400, Turkey

Tel: 90-5318425361

Fax: 90-2626466024

E-mail: nuraycolapkulu@gmail.com https://orcid.org/0000-0002-3033-8702

The article is a revision of the first author's doctoral dissertation which was completed in February 2021.

Copyright $\odot 2021$ The Korean Society for Vascular Surgery

This is an Open Access article distributed under the terms of the Creative Commons Attribution Non-Commercial License (http://creativecommons.org/licenses/by-nc/4.0) which permits unrestricted non-commercial use, distribution, and reproduction in any medium, provided the original work is properly cited.

Cite this article; Vasc Specialist Int 2021. https://doi.org/10.5758/vsi.210065

\section{INTRODUCTION}

Venous thromboembolism (VTE), which includes deep vein thrombosis (DVT) and pulmonary embolism (PE), is one of the most important preventable causes of perioperative mortality in cancer patients undergoing major abdominal surgery $[1,2]$. High-risk patients undergoing abdominal cancer surgery carry a certain risk for VTE both in the early postoperative period and after discharge [3]. Many factors, such as type of cancer, surgical approach, anticancer medical treatments and interventions like venous central/port catheters in the perioperative period play a role in VTE risk classification. In addition, individual characteristics such as race, body mass index and comorbidities are also independent risk factors for the development of the disease $[4,5]$. Extended pharmacological thromboprophylaxis (PTP) up to 
Table 1. Recommended prophylaxis protocols and durations based on the Caprini risk assessment score

\begin{tabular}{lllc}
\hline \multicolumn{1}{c}{ Risk score } & \multicolumn{1}{c}{ Prophylaxis } & Duration & VTE rate $^{\mathrm{a}}$ \\
\hline 0 (Lowest) & Early ambulation & During hospitalization & $<0.5 \%$ \\
$1-2$ (Low) & Mechanical prophylaxis or pharmocological prophylaxis & During hospitalization & $<1.5 \%$ \\
$3-4$ (Moderate) & Mechanical prophylaxis and pharmocological prophylaxis & During hospitalization & $<3 \%$ \\
$5-8$ (High) & Mechanical prophylaxis and pharmocological prophylaxis & $7-10$ days total & $<6 \%$ \\
$>8$ (Highest) & Mechanical prophylaxis and pharmocological prophylaxis & 30 days total & $<6 \%-18 \%$ \\
\hline
\end{tabular}

Mechanical prophylaxis should be used during hospitalization and kept in case of clinical symptoms such as leg swelling.

VTE, venous thromboembolism.

${ }^{\mathrm{a}} 30$ - and 60-day clinical VTE rate based on patient groups and type of surgery without prophylaxis.

Data from https://venousdisease.com/resources [18].

four weeks after major abdominal cancer surgery has been recommended in Western guidelines and literature, but adherence is still limited to some countries or even centers, thus a global standard has not yet been reached [6-11]. For instance, in many prospective studies conducted without extended PTP, the incidence of postoperative VTE has been shown to be much lower in Asian countries than in Western countries, therefore it has been recommended to use extended PTP through identifying high-risk patients [12-15].

The risk of postoperative VTE remains to be high in the first 90 days after the operation. Although prolonged prophylaxis after discharge in the postoperative period is not routinely applied in non-orthopedic surgery, clinicians tend to prolong the duration of prophylaxis up to four weeks, especially in cancer patients undergoing major abdominopelvic surgery. According to the Caprini risk assessment model, first constituted by Caprini et al. [16] in 1991, the duration of prophylaxis should be determined after the patient's risk assessment has been made (Table 1) [17,18].

The aim of this study is to investigate the outcomes and features of patients in terms of DVT development, who underwent curative surgery for colorectal and gastric cancer and received short-term PTP only during perioperative hospitalization period.

\section{MATERIALS AND METHODS}

\section{1) Patient selection}

The records of patients who were surgically treated for colorectal and gastric cancer between January 2017 and December 2019 were reviewed retrospectively. A total of 278 patients were enrolled for this study. Patients who underwent emergency or palliative surgery, had a history of anticoagulant/antiplatelet drug use in the perioperative period, had a prior history of VTE and who were lost to follow-up were excluded. The study was approved by our institution's ethics committee (2013-KAEK-64) with
2018/0505 approval number and the study was also registered to an online open access data base (NCT04709510, clinicaltrials.org). All patients signed a wrtitten consent since there was an extra radiologic imaging method even though it was non-invasive.

\section{2) Study design, protocols for prophylaxis and follow-up}

The study was designed as a retrospective cohort study. Patients who received PTP with the administration of 1 $\mathrm{mg} / \mathrm{kg}$ of enoxaparin sodium in the 12 to 24 hours preoperative period and continued to receive prophylaxis at the preliminary dose only during hospitalization until discharge were included in the study. None of the patients were prescribed low molecular weight heparin (LMWH) or any other anticoagulant/antiplatelet agents for prolonged prophylaxis after hospital discharge. Each patient received mechanical prophylaxis with anti-embolism stockings on the operation day prior to surgery. All of the patients were mobilized within 12 to 24 hours after surgery. Hospital records of patients' demographics and co-morbidities were analyzed. Pathological features such as tumor type, grade of differentiation, tumor sizes, lymphovascular and perineural invasion were classified. Laboratory data of the patients in the preoperative period as well as complete blood count, coagulation tests and tumor markers were recorded.

Postoperative follow-ups were conducted through physical examinations and detailed patient history forms regarding DVT or other VTE events. All patients were examined by bilateral lower extremity duplex ultrasonography (DUS) in order to obtain an objective evidence of DVT presence. DUS was performed randomly when the patient was called for follow-up after the surgery since the patients were collected retrospectively. The procedure was performed via using the linear transducer (12 L) of the GE LOGIQ-9 UItrasound System (Genereal Electric, Boston, MA, USA) in B-mode, imaging beginning from the main femoral vein, applying compression at $1 \mathrm{~cm}$ intervals along the tracing of 
Table 2. Features and potential risk factors of the patients who developed venous thromboembolic event

\begin{tabular}{|c|c|c|c|c|}
\hline \multirow{2}{*}{ Feature } & \multicolumn{2}{|c|}{ Symptomatic DVT } & \multicolumn{2}{|c|}{ Asymptomatic DVT } \\
\hline & Patient \#1 & Patient \#2 & Patient \#3 & Patient \#4 \\
\hline Age, sex & 63 , female & 75 , female & 60 , female & 67, male \\
\hline \multirow[t]{2}{*}{ Chronic disease } & No & Hypertension & Hypertension & Hypertension \\
\hline & & Coronary artery disease & Coronary artery disease & Coronary artery disease \\
\hline Cancer type & Stage II gastric cancer & Stage III right colon cancer & Stage III left colon cancer & $\begin{array}{l}\text { Stage III left colon cancer, } \\
\text { developed metastasis one } \\
\text { year after initial surgery }\end{array}$ \\
\hline Surgery & Total gastrectomy & Right hemicolectomy & Anterior resection & Low anterior resection \\
\hline Caprini score & 6 & 8 & 6 & 8 \\
\hline PTP length (d) & 8 & 8 & 7 & 7 \\
\hline Time of diagnosis & $\begin{array}{l}\text { Postoperative 114th day } \\
\text { during chemotherapy }\end{array}$ & $\begin{array}{l}\text { Postoperative 68th day } \\
\text { during chemotherapy }\end{array}$ & Postoperative 12th month & $\begin{array}{l}\text { Postoperative 13th month } \\
\text { during } 2 \text { nd round of } \\
\text { chemotherapy }\end{array}$ \\
\hline
\end{tabular}

DVT, deep vein thrombosis; PTP, pharmacological thromboprophylaxis.

Table 3. Comparison of demographic characteristics and comorbidities of patients with and without DVT

\begin{tabular}{|c|c|c|c|c|}
\hline \multirow{2}{*}{ Characteristic } & \multicolumn{2}{|c|}{ DVT } & \multirow{2}{*}{ Total $(n=89)$} & \multirow{2}{*}{ P-value } \\
\hline & No $(n=85)$ & Yes $(n=4)$ & & \\
\hline Age & $60(50.0-67.0)$ & $65(62.2-69.2)$ & $89(100.0)$ & 0.21 \\
\hline Sex, male & $54(63.5)$ & $1(25.0)$ & $55(61.8)$ & 0.15 \\
\hline Body mass index $\left(\mathrm{kg} / \mathrm{m}^{2}\right)$ & $26.3(24.0-28.7)$ & $33.2(29.4-35.1)$ & 26.6 & 0.14 \\
\hline \multicolumn{5}{|l|}{ Comorbidities } \\
\hline Hypertension & $22(25.9)$ & $3(75.0)$ & $25(28.1)$ & 0.07 \\
\hline Diabetes & $16(18.8)$ & $0(0.0)$ & $16(18.0)$ & $>0.999$ \\
\hline Coronary artery disease & $0(0.0)$ & $3(75.0)$ & $3(3.4)$ & $<0.001^{*}$ \\
\hline Chronic obstruction pulmonary disease & $2(2.4)$ & $0(0.0)$ & $2(2.2)$ & $>0.999$ \\
\hline Inflammatory bowel disease & $2(2.4)$ & $0(0.0)$ & $2(2.2)$ & $>0.999$ \\
\hline Cancer type & & & & $>0.999$ \\
\hline Colorectal & $59(69.4)$ & $3(75.0)$ & $62(69.7)$ & \\
\hline Gastric & $26(30.6)$ & $1(25.0)$ & $27(30.3)$ & \\
\hline Operation time (mean min) & $200(165-230)$ & $185(180-202)$ & 199 & 0.95 \\
\hline Caprini score & $6(6-7)$ & $7(6-8)$ & 7 & 0.51 \\
\hline Caprini risk score & & & & $>0.999$ \\
\hline Intermediate & $1(1.2)$ & $0(0.0)$ & $1(1.1)$ & \\
\hline High & 78 (91.8) & $4(100.0)$ & $82(92.1)$ & \\
\hline Highest & $6(7.1)$ & $0(0.0)$ & $6(6.7)$ & \\
\hline Length of hospital stay (d) & $8(7-9)$ & $7.5(7-8)$ & 8.0 & 0.67 \\
\hline Postoperative DVT prophylaxis (d) & $7(7-9)$ & $7.5(7-8)$ & 7.0 & 0.87 \\
\hline Adjuvant chemotherapy & $57(67.1)$ & $4(100.0)$ & $61(68.5)$ & 0.30 \\
\hline
\end{tabular}

Values are presented as median (interquartile range) or number (\%).

DVT, deep vein thrombosis.

*Statistically significant $\mathrm{P}<0.05$. 
the femoral vein, deep femoral and popliteal veins.

\section{3) Statistical analysis}

Statistical analyses were performed through SPSS (Statistical Package for the Social Sciences) version 20 (IBM Corp., Armonk, NY, USA). Descriptive statistics were presented as numbers and percentages for categorical variables, mean and standard deviation or median and 25\% to 75\% percentile values for continuous variables. The distribution of categorical variables in the crosstabs was compared with the Pearson Chi-squared test or, in cases where the conditions were not met, with Fisher exact test. The Mann-Whitney $\mathrm{U}$ test was used to compare continuous variables between two independent groups. P-values lower than 0.05 were considered statistically significant.

\section{RESULTS}

A total of 89 patients, 62 with colorectal and 27 with gastric cancers, were included in the study. Median length of hospital stay and PTP were 8 (7-9). The mean followup period of all patients was $21.2 \pm 10.2$ months. DVT was detected in $4(4.5 \%)$ out of 89 patients, where only two of them were symptomatic (2.2\%). Asymptomatic two (2.2\%) were incidentally detected in the DUS performed during follow-up (Table 2). Patients did not undergo any imaging method to evaluate PE, nevertheless according to patients' history no symptomatic PE was found in any of the patients occurred.

There was no significant difference between the two groups regarding age, sex, and body mass index. Thirtyfive (39.3\%) patients had at least one additional chronic disease. Two patients with coronary artery disease who did not use anticoagulant agents in the preoperative period developed asymptomatic DVT and one developed symptomatic DVT $(\mathrm{P}<0.001$; Table 3$)$. No statistically significant difference was found between the two groups in the analysis regarding the tumor location, type of surgery, and mean operative time of the patients (Table 3).

Comparison of histopathological features of the tumors in both groups (Table 4) revealed that two of 8 patients with mucinous adenocarcinoma, one of 76 patients with classical adenocarcinoma, and one of 5 patients with signet ring cell adenocarcinoma developed DVT. The presence of mucinous adenocarcinoma was found to be statistically significant in terms of DVT development $(\mathrm{P}=0.009)$. Vascular invasion and vascular tumor thrombus were also

Table 4. Comparison of histopathological features of tumors between both groups

\begin{tabular}{|c|c|c|c|c|}
\hline \multirow{2}{*}{ Feature } & \multicolumn{2}{|c|}{ DVT } & \multirow{2}{*}{ Total $(n=89)$} & \multirow{2}{*}{ P-value } \\
\hline & No $(n=85)$ & Yes $(n=4)$ & & \\
\hline Histologic type & & & & $0.009^{*}$ \\
\hline Adenocarcinoma & 75 (88.2) & $1(25.0)$ & $76(85.4)$ & \\
\hline Mucinous adenocarcinoma & $6(7.1)$ & $2(50.0)$ & $8(9.0)$ & \\
\hline Signet cell adenocarcinoma & $4(4.7)$ & $1(25.0)$ & $5(5.6)$ & \\
\hline Differentiation & & & & $>0.999$ \\
\hline Low & $20(23.5)$ & $1(25.0)$ & $21(23.6)$ & \\
\hline Medium & $58(68.2)$ & $3(75.0)$ & $61(68.5)$ & \\
\hline Well & $7(8.2)$ & $0(0.0)$ & $7(7.9)$ & \\
\hline Vascular invasion & $29(34.1)$ & $4(100.0)$ & $33(37.1)$ & $0.02^{*}$ \\
\hline Lymphatic invasion & $34(40.0)$ & $3(75.0)$ & $37(41.6)$ & 0.31 \\
\hline Perineural invasion & $33(38.8)$ & $2(50.0)$ & 35 (39.3) & $>0.999$ \\
\hline Tumor size & $55(31-70)$ & $45.0(35-55)$ & $55.0(31-70)$ & $>0.999$ \\
\hline Stage & & & & 0.54 \\
\hline 1 & $12(14.1)$ & $0(0.0)$ & $12(13.5)$ & \\
\hline 2 & $34(40.0)$ & $1(25.0)$ & 35 (39.3) & \\
\hline 3 & $30(35.3)$ & $2(50.0)$ & $32(36.0)$ & \\
\hline 4 & $9(10.6)$ & $1(25.0)$ & $10(11.2)$ & \\
\hline Lymph node metastasis & $39(45.9)$ & $4(100.0)$ & $43(48.3)$ & 0.051 \\
\hline
\end{tabular}

Values are presented as number (\%) or median (25\%-75\%).

DVT, deep vein thrombosis.

${ }^{*}$ Statistically significant $\mathrm{P}<0.05$. 
detected in all patients in the DVT group, while vascular invasion was detected in 29 (34.1\%) of 85 patients who did not develop DVT $(\mathrm{P}=0.02)$. All patients who developed DVT had lymph node metastases, but no significant difference was found in terms of lymph node metastasis and disease stage in both groups ( $\mathrm{P}=0.051$ and 0.54 , respectively).

Table 4 shows the Caprini risk assessment score and categories of the patients, the duration of postoperative prophylaxis, length of hospital stay, ASA scores and other risk factors. The average Caprini score was $6.6 \pm 1.2$ in all patients, and there was no significant difference between the groups $(\mathrm{P}=0.51)$. There was no significant difference between the groups in preoperative hemoglobin, hematocrit, platelet count, prothrombin time, activated partial thromboplastin time, international normalized ratio, and carcinoembryonic antigen or Ca 19-9 values. There was no statistically significant difference in the development of DVT between patients with perioperative central venous catheter or chemotherapy port $(\mathrm{P}=0.99)$.

In addition, blood transfusion was administered in 16 (18.0\%) patients from both groups, including 14 (15.7\%) minor complications patients and $2(2.2 \%)$ major hemorrhagic complications. Hemodynamic stability was achieved by re-operation in two patients with major hemorrhagic complications whereas transfusion of blood products in fourteen patients with minor hemorrhagic complications.

\section{DISCUSSION}

In this retrospective cohort, 89 patients who underwent abdominal surgery for colorectal and gastric cancer and received postoperative short-term PTP, had an overall DVT incidence of $4.5 \%$. Symptomatic DVT were found in $2.2 \%$, and asymptomatic DVT were found in $2.2 \%$ of the cohort. Three patients were under chemotherapy when DVT occurred. It is, therefore, difficult to determine whether these events developed as a result of short PTP or chemotherapy itself. Six (6.7\%) patients who had a Caprini risk score of 9 (very high) and did not receive extended prophylaxis, had not been detected for any VTE events. Many studies have shown the relationship between comorbidity features and increased VTE risks. Co-morbid conditions such as renal failure, lung diseases, morbid obesity, and acute infection have been associated with an increased incidence of VTE in cancer patients $[19,20]$. In our study, one symptomatic and two asymptomatic patients with DVT had coronary artery disease $(P<0.001)$. These patients had no history of using any anticoagulant or antiplatelet treatment for coronary artery disease and however they did not meet any Caprini risk assessment criteria such as history of myocardial infarction or heart failure prior to surgery.
Histological subtypes of some cancers have been associated with increased VTE incidence. Some studies have shown an increased incidence of cancer-associated VTE in mucin-producing adenocarcinoma subtypes of pancreatic, lung, and gastrointestinal tumors [21,22]. Similarly, our findings revealed a significant correlation between the development of DVT and the presence of mucinous adenocarcinoma. Cancer cells produce specific adhesion molecules and can initiate the coagulation process by interacting with procoagulation precursors such as platelets, leukocytes, and endothelial cells. Tumor cells can form thrombus by binding to endothelial cells and platelets. These thrombi can enter the circulation and cause vascular occlusion [23,24]. In our study, vascular invasion and tumor thrombus in adjacent vascular structures were detected in the tumors of all patients diagnosed with DVT $(\mathrm{P}=0.02)$.

It is still controversial whether to administrate extended (4 weeks) or short-term (7-10 days until discharge) PTP in the postoperative period in patients undergoing major abdominal or pelvic cancer surgery (Table 5). In fact, in Eastern populations which have less risk factors than Western counterparts, there are studies favoring for short-term prophylaxis or even observation without prophylaxis, without increasing incidence of VTE [25-27]. In a prospective doublearm study by Lee et al. [12], 548 colorectal cancer patients had only mechanical prophylaxis such as anti-embolism stockings or elastic bandages without using PTP in the perioperative period. During the study period, a total of 12 patients, including asymptomatic ones, developed VTE with and incidence 3\% [14]. In a prospective randomized study by Kim et al. [13], none of the 610 patients, who underwent major abdominal surgery for gastric cancer, received PTP in the perioperative period, and the patients were followed up with DUS in the postoperative period. At the end of the study, the postoperative VTE incidence in the Korean population was determined as $2.4 \%$. In this study, advanced disease stage and advanced age were shown as predictive factors for VTE. Instead of standard PTP, the authors suggested individualized prophylaxis methods after risk stratification in cancer patients [13].

In a randomized clinical study by Vedovati et al. [28], 1-week (short-term) and 4-week (prolonged) PTP were compared after laparoscopic surgery for colorectal cancer. of 113 patients who received short-term prophylaxis, 2 developed symptomatic and 9 developed asymptomatic DVT (total and symptomatic VTE incidences were 9.7\% and 1.7\%). Symptomatic DVT was detected in one patient in the extended prophylaxis group $(0.9 \%$ of VTE incidence in this group). The total incidence of DVT was found to be 5.3\% in all patients included in the study, and PE was not detected in any of the patients. In addition, advanced age was deter- 


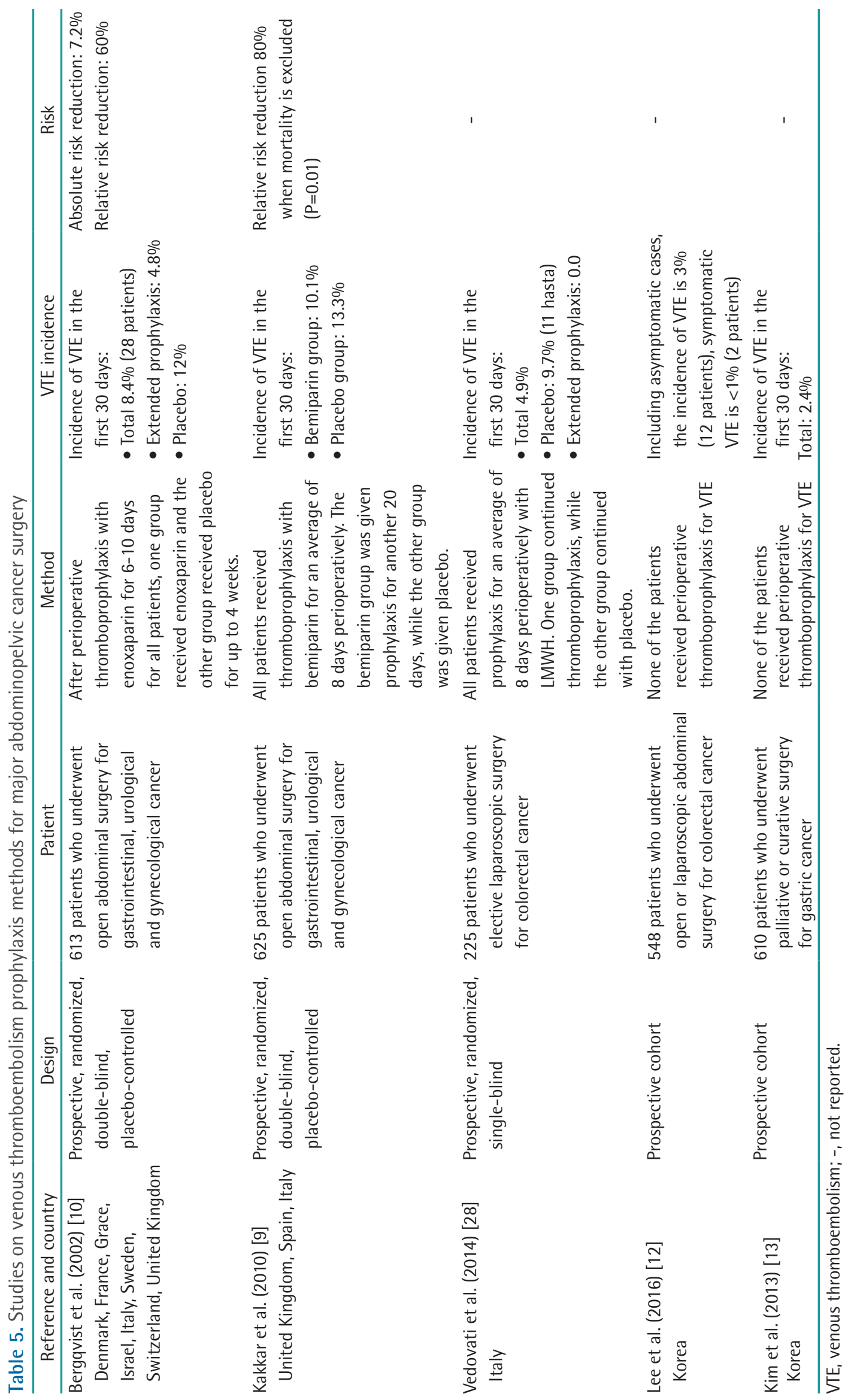


mined as an independent risk factor for the development of VTE [28]. Despite the heterogeneous distribution between groups, the fact that thromboprophylaxis was performed with three different anticoagulant agents is a significant limitation for this study. In the double-blind randomized controlled trial called Cancer, Bemiparin and Surgery Evaluation (CANBESURE) which evaluated extended prophylaxis (bemiparin) for patients undergoing major abdominal or pelvic cancer surgery, no difference was found between the prophylaxis group and the placebo group $(10.1 \%$ in the extended prophylaxis group, $13.3 \%$ in the placebo group, $\mathrm{P}=0.26$ ) [9]. In another randomized controlled clinical trial, Enoxaparin and Cancer (ENOXACAN) II, prolonged prophylaxis with enoxaparin was shown to reduce asymptomatic DVT in the first three postoperative months compared to the placebo group (5.5\% in the prophylaxis group, 13.8\% in the placebo group, $\mathrm{P}=0.010$ ) [10]. In both studies, asymptomatic DVT was detected by venography, and no fatal PE or VTE-related mortality incidents occurred during the follow-up period.

In order to benefit from extended prophylaxis, selecting the patients comprehensively, identifying high-risk patients and determining individual prophylaxis durations are the terms that are debated in the guidelines. Analysis of American College of Surgeons National Surgical Quality Improvement Program (NSQIP) database revealed that chronic steroid use, advanced age, long operative time, length of stay in bed, and major postoperative complications were associated with increased VTE incidence [29]. Such analyses revealing these risk factors have led risk scoring systems that aim to predict postoperative VTE incidence. Therefore, these systems are presumed to provide improved clinical outcomes by determining the risks and administrating targeted prophylaxis strategies.

There are some limitations in our study. First of all, our sample size is rather small to compare two different groups. Secondly, due to the retrospective design, it is possible to miss an asymptomatic event that may have developed in the early postoperative period. Lastly, heterogeneity between patients regarding the timing of DUS may again compromise the results of asymptomatic cases. All events occurred after 4 weeks in all patients who developed DVT. Therefore, with this study, it is not possible to decide whether these symptomatic or asymptomatic events occurred in the first 30 days. Moreover, it is impossible to know that short PTP caused these events. However, based on the patients' history, it is clear that short prophylaxis does not increase symptomatic cases.

\section{CONCLUSION}

Incidence of symptomatic DVT after short-term perioperative PTP does not increase in patients with a Caprini score of 8 and below, who underwent major abdominal surgery due to colorectal and gastric cancer. The incidence of DVT was increased in patients with coronary artery disease, mucinous adenocarcinoma and tumors with vascular invasion.

\section{FUNDING}

None.

\section{CONFLICTS OF INTEREST}

The authors have nothing to disclose.

\section{ORCID}

\author{
Nuray Colapkulu-Akgul \\ https://orcid.org/0000-0002-3033-8702 \\ Ibrahim Ali Ozemir \\ https://orcid.org/0000-0001-8693-9358 \\ Damla Beyazadam \\ https://orcid.org/0000-0001-8678-2004 \\ Orhan Alimoglu \\ https://orcid.org/0000-0003-2130-2529
}

\section{AUTHOR CONTRIBUTIONS}

Concept and design: NCA, OA. Analysis and interpretation: NCA, IAO, OA. Data collection: NCA, DB. Writing the article: NCA, IAO. Critical revision of the article: NCA, IAO, OA. Final approval of the article: all authors. Statistical analysis: NCA. Obtained funding: none. Overall responsibility: NCA, OA.
1) Agnelli G, Bolis G, Capussotti L, Scarpa RM, Tonelli F, Bonizzoni E, et al. A clinical outcome-based prospective study on venous thromboembolism after cancer surgery: the @RISTOS project. Ann Surg 2006;243:89-95.
2) Sandén P, Svensson PJ, Själander A. Venous thromboembolism and cancer risk. J Thromb Thrombolysis 
2017;43:68-73.

3) Serrano PE, Parpia S, Linkins LA, Elit L, Simunovic M, Ruo L, et al. Venous thromboembolic events following major pelvic and abdominal surgeries for cancer: a prospective cohort study. Ann Surg Oncol 2018;25:3214-3221.

4) Trinh VQ, Karakiewicz Pl, Sammon J, Sun M, Sukumar S, Gervais MK, et al. Venous thromboembolism after major cancer surgery: temporal trends and patterns of care. JAMA Surg 2014;149:43-49.

5) Resanovic V, Resanovic A, Savic P, Loncar Z. Which patients require extended thromboprophylaxis after colectomy? Modeling risk and assessing indications for post-discharge pharmacoprophylaxis. World J Surg 2018;42:3458-3459.

6) Lyman GH, Bohlke K, Khorana AA, Kuderer NM, Lee AY, Arcelus Jl, et al. Venous thromboembolism prophylaxis and treatment in patients with cancer: american society of clinical oncology clinical practice guideline update 2014. J Clin Oncol 2015;33:654-656.

7) Gould MK, Garcia DA, Wren SM, Karanicolas PJ, Arcelus Jl, Heit JA, et al. Prevention of VTE in nonorthopedic surgical patients: Antithrombotic Therapy and Prevention of Thrombosis, 9th ed: American College of Chest Physicians Evidence-Based Clinical Practice Guidelines. Chest 2012;141(2 Suppl):e227S-e277S.

8) Fleming F, Gaertner W, Ternent CA, Finlayson E, Herzig D, Paquette IM, et al. The American Society of Colon and Rectal Surgeons Clinical Practice Guideline for the prevention of venous thromboembolic disease in colorectal surgery. Dis Colon Rectum 2018;61:1420.

9) Kakkar VV, Balibrea JL, MartínezGonzález J, Prandoni P. Extended prophylaxis with bemiparin for the prevention of venous thromboembolism after abdominal or pelvic surgery for cancer: the CANBESURE randomized study. J Thromb Haemost
2010;8:1223-1229.

10) Bergqvist D, Agnelli G, Cohen AT, Eldor A, Nilsson PE, Le Moigne-Amrani $A$, et al. Duration of prophylaxis against venous thromboembolism with enoxaparin after surgery for cancer. N Engl J Med 2002;346:975-980.

11) Serrano PE, Parpia $S$, Valencia $M$, Simunovic M, Bhandari M, Levine M. Incidence of delayed venous thromboembolic events in patients undergoing abdominal and pelvic surgery for cancer: a systematic review and metaanalysis. ANZ J Surg 2019;89:12171223.

12) Lee E, Kang SB, Choi Sl, Chun EJ, Kim MJ, Kim DW, et al. Prospective study on the incidence of postoperative venous thromboembolism in Korean patients with colorectal cancer. Cancer Res Treat 2016;48:978-989.

13) Kim JW, Chun EJ, Choi Sl, Park DJ, Kim $\mathrm{HH}$, Bang SM, et al. A prospective study on the incidence of postoperative venous thromboembolism in Korean gastric cancer patients: an inquiry into the application of Western guidelines to Asian cancer patients. PLoS One 2013;8:e61968.

14) Yeo DX, Junnarkar S, Balasubramaniam S, Tan YP, Low JK, Woon W, et al. Incidence of venous thromboembolism and its pharmacological prophylaxis in Asian general surgery patients: a systematic review. World J Surg 2015;39:150-157.

15) Weida D, Patrick LY, Andrew YW. Is it safe to perform operation for colorectal malignancy in Chinese patients without DVT prophylaxis? An 8-year experience from a regional hospital in Hong Kong. Chin Med J (Engl) 2010;123:1973-1975.

16) Caprini JA, Arcelus Jl, Hasty JH, Tamhane AC, Fabrega F. Clinical assessment of venous thromboembolic risk in surgical patients. Semin Thromb Hemost 1991;17 Suppl 3:304-312.

17) Cronin M, Dengler N, Krauss ES, Segal A, Wei N, Daly M, et al. Completion of the updated Caprini Risk
Assessment Model (2013 Version). Clin Appl Thromb Hemost 2019;25: 1076029619838052.

18) Dr. Caprini Resource Center [Internet]. Chicago: Caprini Risk Score; C 2021 [cited 2021 Oct 1]. Available from: https://venousdisease.com/resources/.

19) Khorana AA, Francis CW, Culakova E, Kuderer NM, Lyman GH. Frequency, risk factors, and trends for venous thromboembolism among hospitalized cancer patients. Cancer 2007;110:2339-2346.

20) Connolly GC, Francis CW. Cancerassociated thrombosis. Hematology Am Soc Hematol Educ Program 2013;2013:684-691.

21) Haddad TC, Greeno EW. Chemotherapy-induced thrombosis. Thromb Res 2006;118:555-568.

22) Kucher TV, Oleski SL, Keeney S. Diagnosis of deep venous thrombosis and pulmonary embolus in patients with mucinous variant adenocarcinoma. $\mathrm{J}$ Thromb Haemost 2005;3:591-592.

23) Giavazzi R, Foppolo M, Dossi R, Remuzzi A. Rolling and adhesion of human tumor cells on vascular endothelium under physiological flow conditions. J Clin lnvest 1993;92:30383044.

24) Falanga A, Panova-Noeva M, Russo L. Procoagulant mechanisms in tumour cells. Best Pract Res Clin Haematol 2009;22:49-60.

25) Lee $\mathrm{CH}$, Lin LJ, Cheng $\mathrm{CL}$, Kao Yang YH, Chen JY, Tsai LM. Incidence and cumulative recurrence rates of venous thromboembolism in the Taiwanese population. J Thromb Haemost 2010;8:1515-1523.

26) Jang MJ, Bang SM, Oh D. Incidence of venous thromboembolism in Korea: from the Health Insurance Review and Assessment Service database. J Thromb Haemost 2011;9:85-91.

27) Hata T, Yasui M, lkeda M, Miyake M, lde Y, Okuyama M, et al. Efficacy and safety of anticoagulant prophylaxis for prevention of postoperative venous thromboembolism in Japanese 
patients undergoing laparoscopic colorectal cancer surgery. Ann Gastroenterol Surg 2019;3:568-575.

28) Vedovati MC, Becattini C, Rondelli F, Boncompagni M, Camporese G, Balzarotti R, et al. A randomized study on 1-week versus 4-week prophylaxis for venous thromboembolism after laparoscopic surgery for colorectal cancer. Ann Surg 2014;259:665-669.

29) lannuzzi JC, Young KC, Kim MJ, Gillespie DL, Monson JR, Flem- ing FJ. Prediction of postdischarge venous thromboembolism using a risk assessment model. J Vasc Surg 2013;58:1014-1020.e1. 